\title{
A gripe espanhola em Portugal: a construção da memória. $O$ trabalho médico e a assistência hospitalar
}

\author{
Spanish flu in Portugal: the construction of memory. \\ Medical work and hospital care
}

\section{Alexandra Patrícia Esteves* Sílvia Pinto**}

Resumo: Com este trabalho pretendemos refletir sobre a gripe espanhola em Portugal, procurando evidenciar o seu impacto na sociedade portuguesa e o papel desempenhado pelos profissionais da saúde, em particular pelos médicos, na assistência às vítimas da doença. Atingido pela primeira vaga da epidemia na primavera de 1918, o país, então governado por Sidônio Pais, já sofria as consequências da sua participação na Primeira Guerra Mundial. Era um tempo marcado por carências de toda ordem, em que as convulsões sociais davam expressão ao descontentamento e à revolta da população.

O surgimento e a propagação da pneumônica puseram a nu as fragilidades do país em diversas áreas, nomeadamente, em matéria de prestação de cuidados de saúde, de assistência hospitalar, de higiene pessoal e pública. A impreparação e a incapacidade reveladas pelas autoridades administrativas e sanitárias para conter e combater a doença, apesar das medidas tomadas com esse propósito, motivaram reações violentas e geraram mesmo a desconfiança da população nas entidades públicas. Valeu, na altura, a intervenção de várias instituições, designadamente das Misericórdias, que tomaram a seu cargo a prestação de auxílio aos doentes e às respectivas famílias. Para a (re)construção da memória sobre a pneumônica, uma pandemia durante muito esquecida, e traçar um quadro mais geral da situação que se viveu em Portugal, recorremos a estudos efetuados por médicos e, em particular, à imprensa

* Doutora em História Contemporânea pela Universidade do Minho (UMinho). Professora Auxiliar convidada com agregação, leciona na Universidade Católica Portuguesa (UCP) e na Universidade do Minho. ORCID: https://orcid.org/0000-0003-0660-9485. E-mail: estevesalexandra@gmail.com.

** Mestre em Patrimônio e Turismo Cultural pela Universidade do Minho (UMinho). ORCID: https://orcid.org/00000002-7183-4067. E-mail: silviadfpinto.24@gmail.com. 
da época, reconhecido o importante papel que desempenhou, apesar da censura então vigente não apenas na transmissão de informação sobre o flagelo que afetava o país e o mundo, mas também na crítica e na denúncia do que se considerava merecer reprovação.

Palavras-chave: Pneumônica; Portugal; memória; epidemias; médicos.

Abstract: With this work we intend to reflect on Spanish flu in Portugal, trying to evidence its impact on Portuguese society and the role played by health professionals, particularly doctors, in assisting victims of the disease. Struck by the first wave of the epidemic in the spring of 1918 , the country, then governed by Sidônio Pais, was already suffering the consequences of its participation in the First World War. It was a time marked by shortcomings of all kinds, when social upheavals gave expression to the population's discontent and revolt.

The emergence and spread of Spanish flu exposed the country's weaknesses in several areas, namely in terms of health care, hospital care, personal and public hygiene. The unpreparedness and the inability revealed by the administrative and health authorities to contain and fight the disease, despite the measures taken with this purpose, motivated violent reactions and even generated the population's distrust in public entities. At the time, it was worth the intervention of several institutions, namely "Misericórdias", which took charge of providing assistance to patients and their families. For the (re)construction of memory on Spanish flu, a pandemic that has long been forgotten, and to draw a more general picture of the situation in Portugal, we resorted to studies carried out by doctors and, in particular, the press of the time, recognizing the important role he played, despite the censorship then in effect, not only in transmitting information about the scourge that affected the country and the world, but also in criticizing and denouncing what was considered deserving of disapproval.

Keywords: Spanish Flu; Portugal; memory; epidemics; doctors.

\section{Introdução}

$\mathbf{N}^{s}$ AS ÚLTIMAS DÉCADAS a história da saúde e da medicina conseguiu avanços muito significativos, materializados em obras que permitiram a sua afirmação e consolidação, e que, entre outras matérias, tem dado especial atenção às doenças e às epidemias. ${ }^{1}$ Neste âmbito, têm-se multiplicado os trabalhos sobre instituições e políticas assistenciais, enfermidades e profissionais de saúde.

Durante muito tempo o tema da gripe, em particular, não mereceu grande interesse da parte dos historiadores, apesar da sua recorrência e ancestralidade, além dos milhares de mortos que deixou atrás de si. Trata-se de uma doença que acompanha o ser humano desde

1 COHN, Samuel Kline, Jr. Epidemics. Hate and compassion from the Plague of Athens to Aids. Oxford: Oxford University Press, 2018. 
há cerca de 12.000 anos, mas o primeiro surto documentado ocorreu na Grécia Antiga, no século $\vee$ a.C. Há registro de surtos na Idade Média que se repetiram nos tempos subsequentes e que, como se constata, persistem na contemporaneidade. ${ }^{2}$

Nos finais do século XIX, mais precisamente nos anos de 1889 e 1890, houve uma epidemia de grandes proporções: a gripe russa. Terá começado no Uzbequistão e alastrou-se a todos os países europeus, incluindo Portugal, tendo provocado entre um milhão e um milhão e meio de mortes, incluindo duzentas a trezentas mil na Europa. Em dezembro de 1889 chegou à cidade de Lisboa, onde se calcula que terá infectado metade dos seus habitantes. ${ }^{3}$ Os homens foram mais atingidos do que as mulheres, e as crianças com menos de dois anos de idade foram poupadas. Segundo alguns autores, o contato com essa doença poderá explicar a imunidade das pessoas mais idosas quando do surgimento da pneumônica. Todavia, esse ponto de vista está longe de ser consensual, conquanto que as crianças, que ainda não eram nascidas quando se deu a gripe russa, também não foram muito afetadas por aquela pandemia.

No século XX houve vários surtos de gripe, sendo o mais marcante, pelo elevado número de vítimas, a pneumônica, que também foi chamada "espanhola" ou "bailarina", que assolou o mundo em 1918 e $1919 .{ }^{4}$ Os vários estudos realizados sobre o tema divergem quanto ao lugar onde se manifestou pela primeira vez. Muitos autores localizam o paciente zero no estado do Kansas (EUA), enquanto outros sustentam que a doença surgiu na França, em 1916, ${ }^{5}$ ou, como terceira hipótese, na China. Também não há uma avaliação precisa sobre o número de vítimas que terá oscilado entre 50 e 100 milhões de mortes, embora alguns investigadores arrisquem valores que ultrapassam esses limites. O certo é que chegou aos vários continentes, ainda que os tenha afetado de forma desigual. Inicialmente as populações não se terão apercebido do seu caráter global, circulando a ideia de que se tratava de uma moléstia circunscrita a determinadas zonas, o que pode ajudar a explicar algumas designações que the foram atribuídas, como, por exemplo, "gripe bolchevique", "gripe alemã", "gripe brasileira". ${ }^{6}$ Assim, tal como aconteceu noutras ocasiões a doença funcionou como arma de arremesso, pronta a ser lançada sobre o "inimigo a abater".

A análise da pneumônica não pode ser desprendida do contexto em que se manifestou e, em particular, da coincidência temporal com a Primeira Guerra Mundial. Os primeiros

2 Sobre a antiguidade da gripe, leia-se: LINDEMANNN, Mary. Medicina e sociedade no início da Idade Moderna - Novas abordagens da história europeia. Lisboa: Editora Replicação, 2002. p. 60.

3 SOARES, Antônio Augusto de Castro. Gripe ou influenza. Porto: Typographia de Pereira e Cunha, 1892. p. 46.

4 CROSBY, Alfred. America's Forgotten Pandemic: The Influenza of 1918. Cambridge: Cambridge University Press, 2003.

5 OXFORD, John. The so-called great Spanish influenza pandemic of 1918 may have originated in France in 1916. Philosophical Transactions of The Royal Society, Biological Sciences, v. 356, n. 1416, p. 1.8571.859, 2001; PHILLIPS, Howard; KILLINGRAY, David. Introduction. In: PHILLIPS, Howard; KILLINGRAY, David (orgs.). The Spanish influenza pandemic of 1918-19: new perspectives. London: Routledge, 2003, p. 1-25. BARRY, John M. The Great Influenza: The Story of the Deadliest Pandemic in History. New York: Penguin Books, 2004; BRISTOW, Nancy K. American Pandemic: The Lost Worlds of the 1918 Influenza Epidemic. New York: Oxford University Press, 2012.

6 Sobre a pneumônica no Brasil, leia-se: SOUZA, Christiane Maria da Cruz. A gripe espanhola na Bahia: saúde, política e medicina em tempos de epidemia. 2007. Tese (Doutorado em História das Ciências e da Saúde) - Casa Oswaldo Cruz-Fundação Oswaldo Cruz, Rio de Janeiro, 2007. 
casos registraram-se em março de 1918 e o primeiro surto prolongou-se até junho desse ano. Segundo Laura Spinney, não há descontinuação entre a primeira e segunda vaga, visto que, na Europa, continuou a grassar no mês de julho. Por exemplo, Mustafa Kemal, Ataturk, fundador e primeiro presidente da República da Turquia, ficou retido em Viena (Áustria) por causa da epidemia. ${ }^{7}$ Em agosto apareceu a segunda vaga, manifestando-se em três lugares do Atlântico: Freetown (Serra Leoa); Boston (EUA) e Brest (França). Nos meses seguintes espalhou-se pelo continente americano e pela costa ocidental africana. Em setembro percorria praticamente toda a Europa, norte da Ásia e Índia. Em outubro chegou à China. Em 1919 houve a terceira vaga e, em alguns países, terá ocorrido a quarta.

Ao longo do presente trabalho, pretendemos expor, além das medidas preventivas e remediativas que foram adotadas para enfrentar a gripe espanhola, as dificuldades que se faziam sentir no domínio da saúde, em particular na assistência hospitalar e na prestação de cuidados médicos. Para a consecução deste propósito, socorremo-nos, entre outras fontes, da imprensa, que, além de denunciar as limitações e as carências de toda a ordem que a pandemia evidenciou, não deixou de enaltecer o esforço do pessoal de saúde, designadamente dos médicos, bem como de teses apresentadas à Escola Médico-Cirúrgica do Porto, nas quais constam propostas destinadas a minorar os efeitos de epidemias que ocorressem no futuro. Trata-se, por conseguinte, de uma análise que dá especial relevo à intervenção do médico na construção da memória sobre a gripe espanhola em Portugal.

\section{A pneumônica em Portugal}

EM PoRTugal a pneumônica terá causado cerca de 60 mil mortes, embora alguns autores apontem para 100 mil óbitos. ${ }^{8} \mathrm{~A}$ verdade é que, nos anos da pandemia, se registou no país um aumento exponencial do número de óbitos, conforme se pode observar no gráfico $1 .{ }^{9}$

7 SPINNEY, Laura. El jinete Pálido. 1918: La epidemia que mudou el mundo. Barcelona: Crítica, 2018.

8 SOBRAL, José Manuel e LIMA, Maria Luísa. A epidemia da pneumônica em Portugal no seu tempo histórico. Ler História, n. 73, p. 45-66, 2018; ANDRADE, Helena Rebelo-de-; FELISMINO, David. A pandemia de gripe de 1918-1919: um desafio à ciência médica no princípio do século XX". Ler História, p. 67-92, 2018; BANDEIRA, Mário Leston. A sobremortalidade de 1918 em Portugal: análise demográfica. In: SOBRAL, José Manuel; LIMA, Maria Luísa; CASTRO, Paula; SOUSA, Paulo Silveira e (Coords.). A pandemia esquecida: olhares comparados sobre a pneumônica. Lisboa: Imprensa de Ciências Sociais, 2009, p. 131-154. FRADA, J.M. A gripe pneumônica em Portugal Continental (1918): estudo socioeconômico e epidemiológico. Lisboa: Sete Caminhos, 2005.

9 A gripe pneumônica tem merecido a atenção de historiadores e de outros cientistas sociais em Portugal: CORREIA, Ana Maria. A resposta em Coimbra à epidemia de pneumônica de 1918-1919 sob o olhar de um periódico local. História, Ciências, Saúde - Manguinhos, v. 25, n. 3 p. 679-694, jul.-set. 2018. DAVID DE MORAIS, João Augusto. Surtos epidêmicos ocorridos em Portugal na primeira metade do século XX: abordagem histórico-epidemiológica. III - Gripe pneumônica. Medicina Interna, n. 19, p. 97-104, 2012. GIRÃO, Paulo. A pneumônica no Algarve (1918). Casal de Cambra: Caleidoscópio, 2003; SEQUEIRA, Álvaro. A pneumônica. Spanish influenza. Medicina Interna, v. 8, n. 1, 2001, p. 49-55. Atente-se às obras: FERREIRA, Antero (coord.). A gripe espanhola de 1918. Casa de Sarmento - Centro de Estudos do Patrimônio. Universidade do Minho, 2020; e SILVA, Helena da; PEREIRA, Rui M.; BANDEIRA, Filomena (coord.). Centenário da gripe pneumônica. A pandemia em retrospectiva. Portugal 1918-1919. Lisboa: IGAS, 2019. 
Gráfico 1 - Número de óbitos registrados em Portugal (1915-1919)

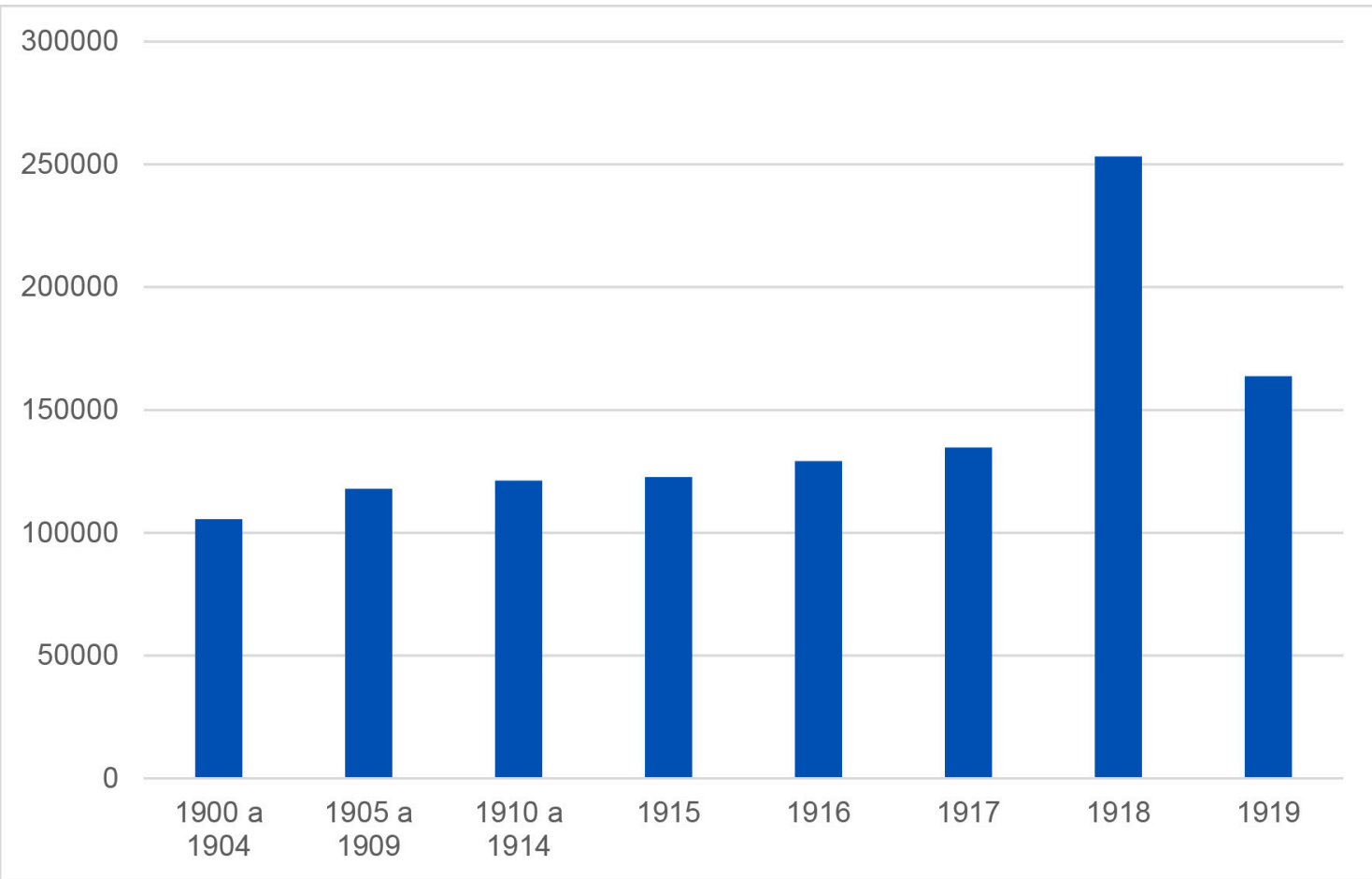

Fonte: INE, Anuário Estatístico de Portugal, Demografia, 1919.

O primeiro surto chegou a Portugal na primavera de 1918, mantendo-se até julho. O segundo apareceu em finais de agosto e durou até dezembro. Em maio de 1919, surgiu a terceira vaga e, segundo a perspectiva de alguns autores, que partilhamos, houve um quarto surto no outono/inverno de 1919 e 1920.

A participação na I Guerra Mundial agravou a situação de Portugal, já de si muito complicada, nos planos político, econômico e social. A fome e a miséria grassavam em vários pontos do país. Bens essenciais como azeite, farinha, açúcar, legumes e leite escasseavam e, devido à especulação e aos atravessadores, atingiam preços exorbitantes e passaram a ser racionados. Por ser recomendado para tratar a gripe, apelava-se para que o leite fosse reservado para os que dele precisavam. Em muitos lugares, as mercearias encerraram por não terem produtos para vender. Quando a pandemia chegou, foi decidido que as farmácias deviam estender os seus horários de atendimento, mas algumas não tinham as substâncias receitadas para tratar a enfermidade e outras acabaram por fechar as portas porque os seus proprietários ou empregados também adoeceram. Para minorar a penúria que atingia grande parte da população, houve necessidade de reforçar as sopas econômicas e outras respostas sociais.

Na altura, Portugal também se debatia com graves problemas na área da saúde. Em várias regiões, a pneumônica coincidiu com epidemias de varíola e tifo epidêmico, sobrecarregando os hospitais, que já funcionavam em condições muito precárias e com muitas limitações. ${ }^{10}$

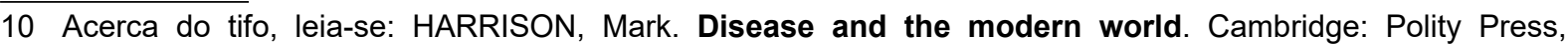


Em 1917 o país (Portugal continental e os arquipélagos dos Açores e da Madeira) dispunha de 231 estabelecimentos hospitalares, mas de reduzida dimensão e quase todos geridos pelas Misericórdias.

Gráfico 2 - Hospitais existentes em Portugal, por distrito, nos anos de 1917 e 1919

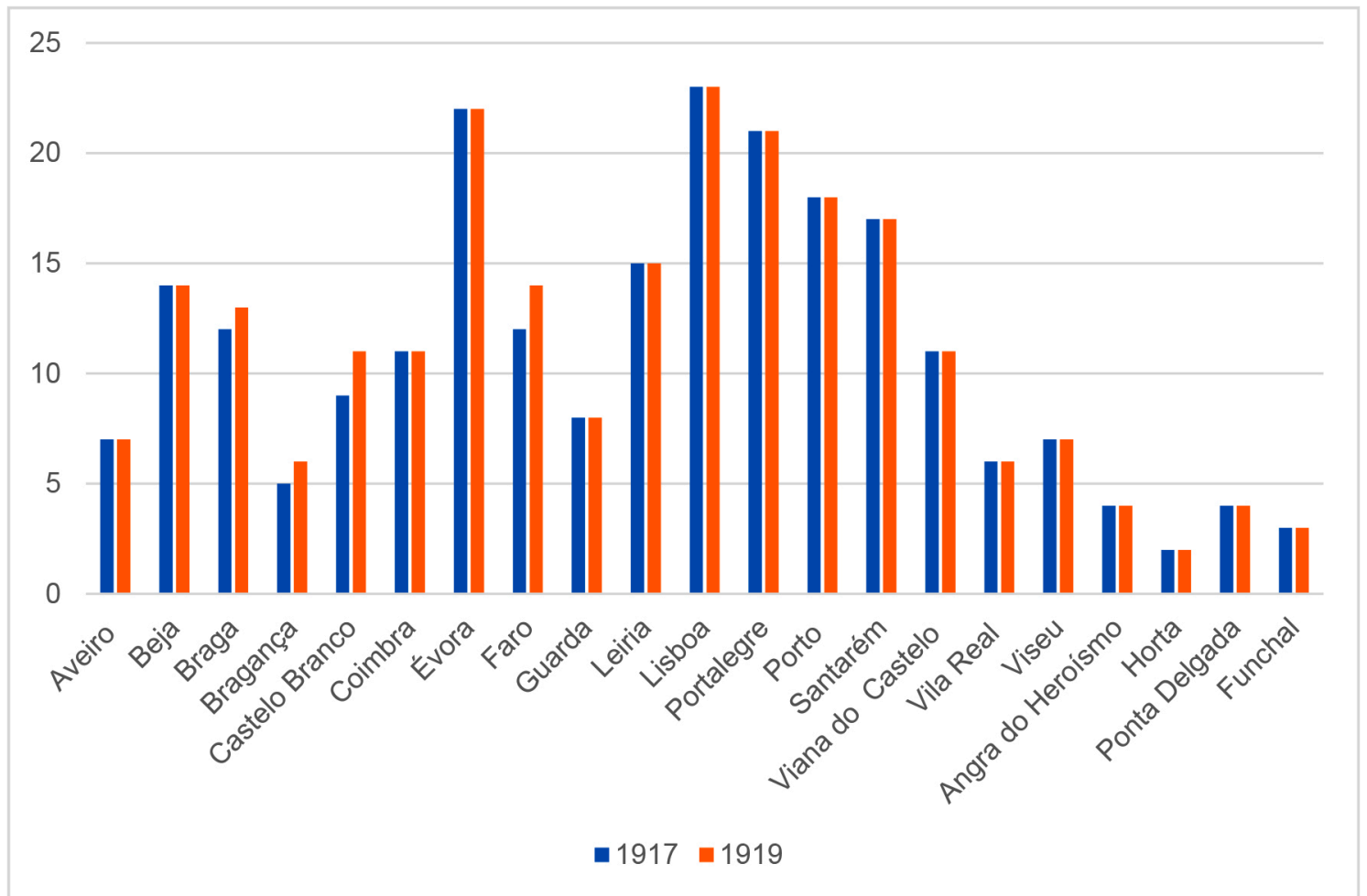

Fonte: INE, Anuário Estatístico de Portugal, Beneficência e Assistência, 1917 e 1919.

Conforme se poderá observar no gráfico 2, os distritos com mais hospitais eram Lisboa, Évora, Portalegre, Porto e Santarém, o que tem a ver, essencialmente, com a dimensão das circunscrições administrativas. Quanto ao número de doentes, os mais concorridos eram os de Lisboa, Porto, Braga, Évora e Coimbra. Havia ainda os hospitais militares. Em 1919 foram criados mais estabelecimentos nos distritos de Braga, Bragança, Castelo Branco e Faro.

Em relação à frequência hospitalar, apresentada no gráfico 3 , constata-se que, depois da diminuição registrada até 1917, houve um crescimento em 1918, explicado pelos internamentos provocados pela pneumônica.

2009. p. 153-156; UJVARI, Stefan Cunha. A história e suas epidemias. A convivência do homem com os microrganismos. Rio de Janeiro: Editora Senac Rio; Editora Senac São Paulo, 2003. p. 71-77. Consulte-se: JORGE, Ricardo. Tifo exantemático ou tabardilho. Relatórios apresentados ao conselho superior de Higiene. Lisboa: Imprensa Nacional, 1918; ALMEIDA, Eurico. O tabardilho em Braga. Porto: Tipografia Belenense, 1920. 
Gráfico 3 - Frequência dos hospitais portugueses (1915-1918)

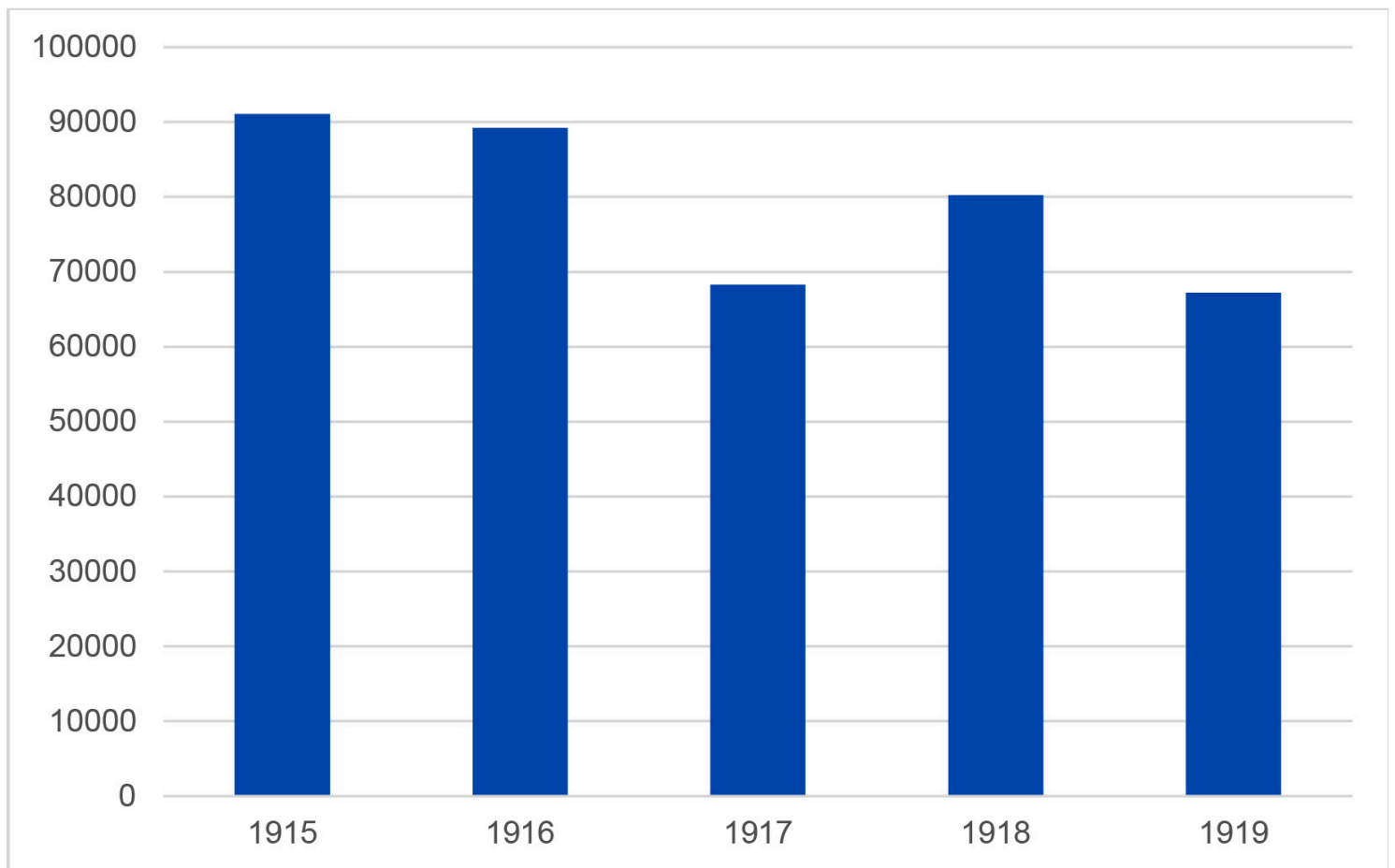

Fonte: INE, Anuário Estatístico de Portugal, Beneficência e assistência, 1919.

As limitações que dificultavam o funcionamento dos hospitais eram de natureza diversa, indo desde a falta de recursos materiais e humanos até a superlotação. Ora, num contexto de pandemia, como aconteceu com a pneumônica, essas fragilidades tornavam-se mais evidentes, obrigando os responsáveis pela sua gestão a encaminhar enfermos para hospitais militares e para outras estruturas adaptadas, designadamente antigos conventos e escolas.

Já nos tempos que antecederam a pandemia, era notória, em Portugal, a insuficiência de profissionais de saúde, sobretudo de médicos. Alguns também não resistiram à doença, ficando uma parte significativa da população entregue a sua sorte. Os cursos de medicina eram ministrados nas universidades de Lisboa, Coimbra, e Porto, mas não formavam médicos em número suficiente para satisfazer as necessidades em matéria de cuidados de saúde. Várias instituições, muitas vezes através da imprensa, lamentavam a falta de recursos humanos, incluindo pessoal de enfermagem, para combater a pneumônica e outras epidemias. Uma dificuldade acrescida tinha a ver com o fato de os médicos terem que se dividir entre os hospitais e as casas dos pacientes. Acontecia que, àquela altura, a gente mais abastada evitava deslocar-se ao hospital para tratar dos seus males, por se tratar de um espaço conotado com a pobreza, e optava por ser assistida em casa. Essa circunstância propiciava o contato de pessoas infectadas com familiares e pessoas próximas e, consequentemente, aumentava o risco de contágio e de propagação da doença. Não é de admirar, por isso, que os médicos e enfermeiros estivessem entre as principais vítimas da gripe espanhola, o que levou à paralisação de vários hospitais. Em várias localidades, valeu a intervenção da 
Cruz Vermelha Portuguesa, que montou hospitais de campanha e, com a colaboração dos bombeiros, assegurou o transporte de doentes. Por exemplo, no conselho de Esposende, situado no norte de Portugal, havia dois médicos, mas, quando a pneumônica já grassava com grande violência, um deles adoeceu, ficando a assistência a 17 mil pessoas a cargo de apenas um clínico! ${ }^{11}$

A partir da segunda metade do século XIX, assiste-se ao reconhecimento do estatuto e da importância dos médicos. Assumem um papel preponderante no combate a epidemias e a doenças que grassavam de forma endêmica na sociedade portuguesa, ou que atingiam a categoria de flagelos sociais, como a doença mental; empenham-se na sensibilização das autoridades competentes para a necessidade de investir no melhoramento das condições de vida dos grupos sociais mais carentes, apelando à aposta na medicina social e preventiva; envolvem-se na divulgação dos cuidados de higiene, como forma de evitar o surgimento e a propagação de enfermidades.

Por todo o país, mas especialmente nas terras mais isoladas, onde as populações continuavam a confiar sua saúde a "charlatães" e curandeiros, ainda havia uma certa desconfiança relativamente aos diagnósticos e tratamentos prescritos pelos médicos. ${ }^{12}$ Por outro lado, a falta de hábitos de higiene e algumas práticas e costumes, que teimavam em permanecer muito arraigados na sociedade portuguesa, contribuíam, sobremaneira, para o surgimento e a disseminação de todo tipo de enfermidades (sarampo, febre tifoide, diarreias, difteria etc.). ${ }^{13} \mathrm{O}$ uso da água, fosse para a higiene pessoal, fosse para a limpeza das casas, não era muito frequente, além de que, muitas vezes, as habitações, sobretudo nos meios rurais, eram partilhadas com os animais. A casa urbana também não primava pelo asseio. No século XIX e nos inícios do seguinte, no Porto, proliferavam as ilhas, e, em Lisboa, os pátios onde residiam operários. ${ }^{14} \mathrm{~A}$ falta de higiene não se restringia aos espaços privados, mas observava-se também nos lugares públicos. Daí o constante apelo aos cuidados de limpeza, para prevenir e combater enfermidades que encontravam na imundície o cenário perfeito para sua propagação.

Quando a pneumônica começou a alastrar, os médicos não conseguiam chegar a acordo sobre o diagnóstico da moléstia com que estavam a lidar. Uns entendiam que se estava perante casos de febre "dos três dias", ou seja, de dengue, enquanto outros chegaram

11 O Espozendense, Esposende, n. 595, 26 set. 1918.

12 ESTEVES, Alexandra. O impacto da pneumônica nalguns conselhos do Alto Minho. CEM, n. 5, p. 165181, 2014; ESTEVES, Alexandra. A pneumônica no norte de Portugal: impacto e medidas. In: ESTEVES, Alexandra (coord.). Sociedade e pobreza: mecanismos e práticas assistenciais (séculos XVII-XX). A época contemporânea. Vila Nova de Famalicão: Húmus, 2018. p. 145-164.

13 PEREIRA, Ana Leonor; PITA, João Rui. A higiene: da higiene das habitações ao asseio pessoal. In: VAQUINHAS, Irene (coord.). História da vida privada em Portugal. Lisboa: Círculo de Leitores, 2011. p. 92116; COSME, João. As preocupações higieno-sanitárias em Portugal ( $2^{\mathrm{a}}$ metade do século XIX e princípio do século XX). Congresso Internacional de História Territórios, Culturas e Poderes. Atas. NW. Noroeste. Revista de História, v. II. Braga: Núcleo de Estudos Históricos, Universidade do Minho, 2007. p. 707-722.

14 Sobre a casa portuguesa desse período, leia-se: CASCẪ, Rui. Em casa: o quotidiano familiar. In: VAQUINHAS, op. cit., p. 222-252; SEIXAS, Paulo Castro. 2011. Illhas e novos condomínios no Porto do século XX. Reflexos do passado, interrogações do presente. In: SANTOS, Carlota (coord.). Família, espaço e patrimônio. Porto: CITCEM, 2011. p. 495-502. 
a aventar a possibilidade de se tratar de peste pneumônica. Por sua vez, Ricardo Jorge, então diretor-geral da Saúde, não teve dúvidas em declarar que se tratava de influenza. ${ }^{15}$ Essa hesitação inicial, que não foi exclusiva de Portugal, terá prejudicado o combate à enfermidade.

A primeira vaga de pneumônica foi encarada com alguma ligeireza, dado o seu caráter benigno, apesar de ter afetado um número considerável de pessoas, mas sem causar muitas vítimas mortais. Em junho, a Direção-Geral da Saúde solicitou aos delegados de saúde dos diferentes distritos do país que a informasse da ocorrência de casos da "epidemia que grassa em Espanha" nas respectivas circunscrições administrativas. Naquele mês foram identificados muitos infectados no Alentejo, nomeadamente em Vila Viçosa, Estremoz, Redondo, Terrugem e Assumar, bem como nas cidades de Porto e Lisboa. ${ }^{16}$ Nas cadeias do Aljube e de Monsanto, em Lisboa, registraram-se 18 e 50 casos, respectivamente. A partir desses estabelecimentos prisionais, a doença terá passado para a população restante.

A pneumônica regressou em finais de agosto e rapidamente se espalhou pelo país, embora de forma desigual. Foi sugerida a hipótese de ter começado nos estabelecimentos militares, atingindo, depois, a sociedade civil. De fato, os primeiros casos foram detectados no quartel de artilharia n. ${ }^{\circ}$, na Serra do Pilar, em Vila Nova de Gaia. Em finais de setembro, estava em Lisboa, registrando-se então os primeiros internamentos, que atingirão números elevados durante o pico da pandemia, ou seja, nos meses de outubro e novembro. Aliás, por essa altura, mais precisamente a 27 de setembro de 1918, a Direção-Geral da Saúde transmitia as primeiras orientações referentes à hospitalização dos doentes, à higiene pública e pessoal, à assistência médica e ao apoio aos doentes pobres.

Em outubro, a pneumônica já tinha alastrado a todo o país. ${ }^{17}$ No princípio desse mês, a Direção-Geral da Saúde estabeleceu um conjunto de medidas, que, no entanto, vieram a revelar-se ineficientes: obrigatoriedade de os médicos comunicarem àquela entidade todos os casos diagnosticados; criação de hospitais provisórios, o que demonstra o reconhecimento de que os hospitais gerais existentes não eram capazes de corresponder às necessidades; abastecimento das farmácias com as substâncias medicamentosas indispensáveis para o tratamento da doença, o que não se concretizou; controle das migrações; divisão dos conselhos em áreas médico-farmacêuticas; mobilização dos médicos, incluindo os aposentados; sensibilização da população para a formação de "comissões de socorro".

A progressão da doença acompanhou os deslocamentos das pessoas: seguiu os soldados que obtiveram licença para regressarem às terras de origem; os trabalhadores rurais, que, em setembro, iniciavam as colheitas, recorrendo à solidariedade vicinal, o que

15 JORGE, Ricardo. A influenza, nova incursão peninsular: relatório apresentado ao Conselho Superior de Higiene. Lisboa: Imprensa Nacional, 1918. JORGE, Ricardo. A influenza e a febre dos papatazes. Lisboa: Imprensa Nacional, 1918.

16 O Espozendense, Esposende, n. 582, 20 jun. 1918.

17 MADEIRA, Affonso Henriques Malheiro. A gripe. Estudo de epidemiologia. Porto: Tipografia Vasconcelos, 1921. p. 71. 
propiciava ajuntamentos consideráveis de pessoas; os marinheiros e pescadores na faina do mar; os veranistas de regresso das estâncias termais e balneares. ${ }^{18}$

Na primeira fase da pandemia, o diretor-geral da Saúde achou que feiras e festividades não deviam ser suspensas, para evitar o pânico e os prejuízos que adviriam para a vida das pessoas. No entanto, perante o agravamento da situação sanitária, alguns administradores de conselho fizeram publicar editais com as seguintes decisões e orientações: encerramento de salas de espetáculo; proibição de procissões e cortejos fúnebres; fechamento de cafés e clubes; sepultamento dos cadáveres no prazo de 24 horas após a declaração de óbito; reforço da higiene pública e privada; comunicação ao subdelegado de saúde de todos os óbitos causados pela pneumônica, para se proceder à desinfecção das casas dos falecidos; participação ao poder judicial de todas as transgressões das normas estabelecidas. ${ }^{19}$ No âmbito das medidas preventivas, recomendava-se que fossem evitados os espaços fechados, os ajuntamentos de pessoas e que se cuidasse da alimentação. As feiras e os mercados não foram interrompidos, mas as festas e romarias acabaram por ser proibidas pelos governadores civis. ${ }^{20}$

Enquanto durou a pandemia, eram frequentes as notícias sobre o desaparecimento de famílias inteiras e, consequentemente, a sociedade era alertada para o problema da orfandade, que atingiu uma dimensão deveras preocupante. O pavor causado pela doença, devido ao elevado número de mortes, sobrepunha-se ao causado pela guerra. A 10 de novembro de 1918, o jornal O Algarve escrevia: "Desapareceu o pavor da guerra; já não se choram os nossos compatriotas em armas ou nas prisões inimigas!"21 E acrescentava: "Os lutos da guerra são muito benignos perante os lutos da gripe pneumônica". ${ }^{22}$

O combate à pneumônica era dificultado por diversos fatores: desconhecimento que ainda persistia relativamente ao seu desenvolvimento; impreparação e falta de coordenação entre as autoridades médicas e sanitárias; escassez ou inexistência de substâncias medicamentosas eficazes; ausência de condições de salubridade das casas e de hábitos de higiene pessoal; carência de médicos, cirurgiões e outros profissionais de saúde; reduzida dimensão e falta de condições dos hospitais; insuficiência de farmácias para atender às necessidades dos doentes. Mesmo assim, houve conjugação de esforços no combate à enfermidade, envolvendo não só as autoridades administrativas e sanitárias, mas também a sociedade civil. ${ }^{23} \mathrm{~A}$ criação de "comissões de socorros" e as atividades beneméritas são alguns dos exemplos que mostram o empenho da população na mitigação dos efeitos do flagelo. Mas também não faltaram manifestações de descontentamento contra os médicos e contra as autoridades sanitárias, sobretudo nas zonas mais isoladas e rurais, onde a mortandade foi mais elevada.

18 COSTA, Celestino da. Estudo da gripe epidêmica. Porto: Tip. a vapor da Enciclopédia Portuguesa, 1920. p. 76.

19 Maria da Fonte, 20 out. 1918.

20 O Algarve: semanário independente, Faro, n. 353, 27 out. 1918.

21 O Algarve: semanário independente, Faro, n. 355, 10 nov. 1918.

22 O Algarve: semanário independente, Faro, n. 355, 10 nov. 1918.

23 SOUSA, Paulo Silveira e; CASTRO, Paula; LIMA, Maria Luísa; SOBRAL, José Manuel. Responder à epidemia: estado e sociedade civil no combate à gripe pneumônica (1918-1919). Revista História das Ideias, n. 29, p. 469-500, 2008. 
A Igreja Católica, juntamente com outras instituições, desempenhou um papel relevante no combate à pandemia. Segundo a imprensa, no mês de novembro, a pneumônica dava mostras de estar regredindo na cidade de Faro, no Algarve, região do sul de Portugal, mas continuava a grassar noutros lugares da região. Perante esta circunstância, o prelado da diocese D. Antônio Barbosa Leão promoveu uma reunião das Senhoras da Caridade com o objetivo de aumentar o número de voluntários, o que foi conseguido, que se dedicariam a angariar donativos para suprir as carências dos enfermos. A cidade de Faro foi, então, dividida em oito zonas. Em cada uma existia uma comissão que estava incumbida de visitar os doentes e averiguar as suas necessidades (roupa, dinheiro ou alimento). Foram realizadas visitas domiciliares e procedeu-se à distribuição de carne, pão, arroz, grão, milho, toucinho, roupas e substâncias medicamentosas. ${ }^{24}$

$\mathrm{Na}$ assistência à população, importa destacar também a atuação da Cruz Vermelha Portuguesa e das Misericórdias, que, em várias localidades, receberam os doentes nos seus hospitais, auxiliaram na montagem de estruturas provisórias e procuraram combater a fome e atenuar a miséria que atingiam uma parte considerável da população, que, mesmo assim, foi solidária e não deixou de acudir os mais precisados.

A pneumônica regressou a Portugal em 1919. Em maio já grassava com grande intensidade em Badajoz, o que preocupava as autoridades portuguesas. No mesmo mês, atingiu alguns lugares, mas com caráter benigno. ${ }^{25} \mathrm{Na}$ mesma altura, reapareceram o tifo e a varíola nalguns lugares do norte do país, designadamente em Guimarães.

Segundo alguns autores, Portugal terá sofrido uma quarta vaga de pneumônica no outono/inverno de 1919 e 1920. De fato, em meados de outubro, era noticiada a existência de casos no país e no estrangeiro, tendo-se registrado no distrito de Braga um número elevado de óbitos. ${ }^{26}$ Em fevereiro de 1920, foram identificados vários casos em Guimarães. ${ }^{27}$

Através do registro nosográfico dos hospitais civis, verificamos que, no distrito de Braga foram internadas 521 pessoas com doenças epidêmicas, um dos números mais elevados do país no ano de 1919, apenas ultrapassado pelo Porto, conforme se pode ver no gráfico 4. Contudo, há dois aspectos a considerar: os hospitais civis de Lisboa e o hospital da Universidade de Coimbra, bem como outros de menor dimensão, não disponibilizaram os seus dados, o que torna seus resultados questionáveis; esses números poderão não ter a ver apenas com a pneumônica, mas com outros surtos epidêmicos que se faziam sentir no país, nomeadamente de varíola e de tifo epidêmico. As doenças epidêmicas foram as principais causadoras dos 10.647 internamentos registrados no país. Porém, é de salientar também o elevado número de doenças não identificadas (10.823).

24 O Algarve, semanário independente, Faro, n. 355, 10 nov. 1918

25 O Mensageiro, Leiria, n. 229, 16 maio 1919.

26 O Espozendense, Esposende, 16 out. 1919.

27 Comércio de Guimarães, Guimarães, 28 maio 1920. 
Gráfico 4 - Número de doentes internados por doença epidêmica (1919)

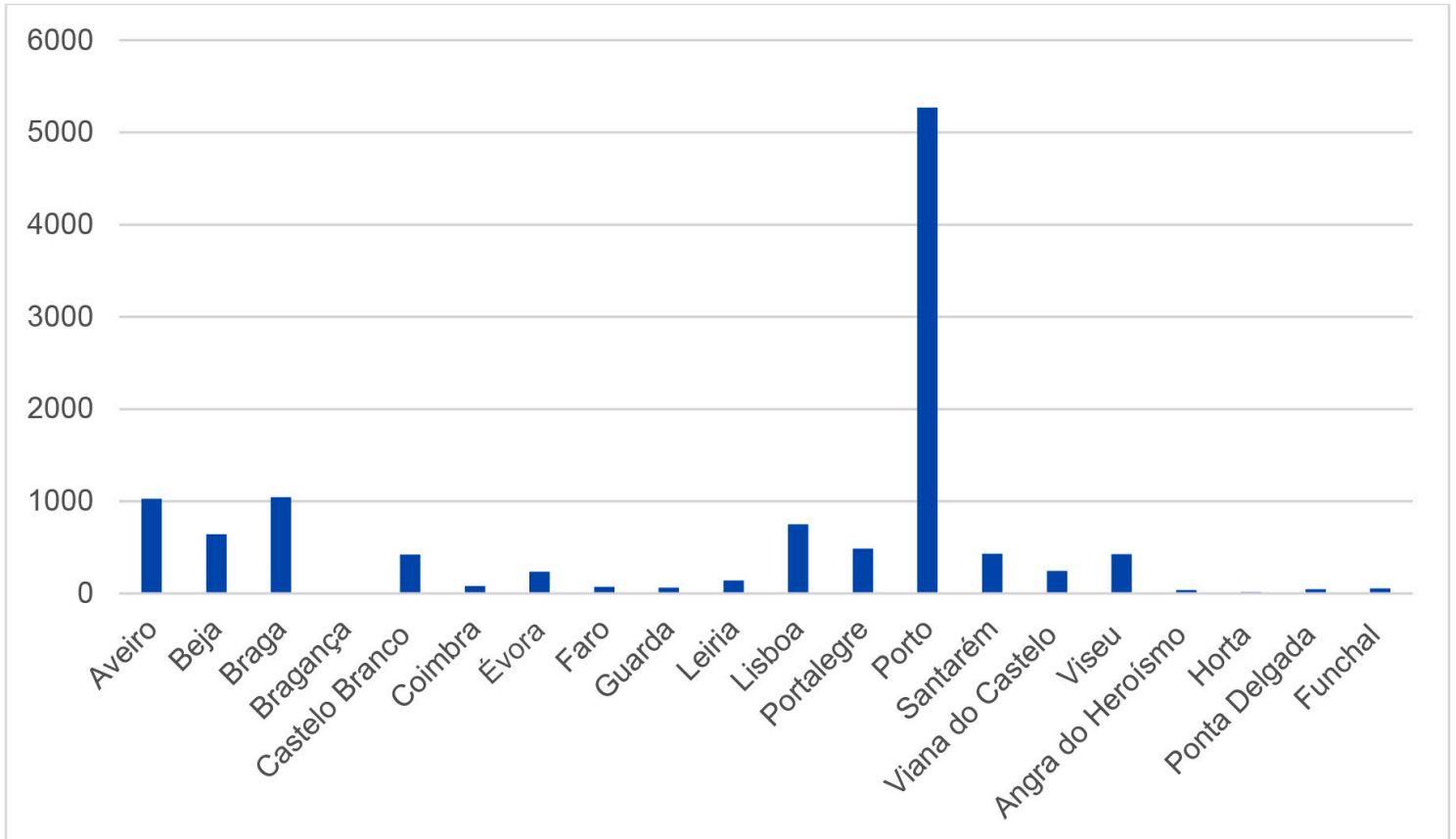

Fonte: INE, Anuário Estatístico de Portugal, Beneficência e Assistência, 1919.

Não há consenso sobre se a pneumônica atingiu por igual os vários estratos sociais, ou se, pelo contrário, afetou mais uns do que outros. O diretor-geral da Saúde, corroborado pelo médico Almeida Garrett, sustentava que atacou sobretudo os mais carentes. Outros clínicos defendiam que a gripe não discriminava ninguém. Todavia, é inegável que os mais pobres se encontravam numa situação mais frágil, ditada por um quotidiano marcado por inúmeras privações. Com a suspensão do funcionamento das fábricas e das oficinas e a redução da atividade agrícola, as famílias viram o seu rendimento minguar ou desaparecer, a miséria tomou conta de muitos lares; até o alimento dos animais começou a escassear e a fome também se abateu sobre eles. Os pescadores, tomados pelo medo, não saíam para o mar, e assim começou a faltar mais uma fonte de alimento. O certo é que, em diversas regiões, a pandemia obrigou à paralisação de praticamente todas as atividades, sobretudo nos meses de outubro e novembro de 1919.

À semelhança do que aconteceu noutras partes do país, a resposta hospitalar existente na capital rapidamente atingiu o limite e foi necessário transformar escolas em hospitais. Em algumas localidades, como em Leiria, foi sugerida a adaptação dos hotéis para acolherem doentes. O problema maior é que, em diversos lugares, a capacidade dos hospitais já estava esgotada por causa da incidência de outras epidemias, que já tinham obrigado à conversão de várias estruturas em hospitais provisórios. Foi o que sucedeu em Viana do Castelo, com a varíola, e, em Guimarães, com o tifo. Nesta cidade, a epidemia chegou em finais de setembro, sendo os enfermos encaminhados para o hospital da Misericórdia local. No entanto, poucos dias depois já era utilizado outro espaço para acolher os pacientes. Mesmo assim, os médicos 
denunciavam e insurgiam-se contra a resistência dos doentes ao internamento. Conotado com a pobreza, o hospital era evitado pelos mais abastados, que preferiam o tratamento em casa, na companhia dos familiares, mas recebiam a visita de amigos e vizinhos, o que ajudava a disseminar a doença. ${ }^{28}$

Apesar das hesitações relativamente ao diagnóstico da enfermidade, os conhecimentos dos médicos sobre a gripe já eram significativos: sabiam que era uma doença que já grassava em Portugal desde a Idade Média; avisavam, tal como hoje, que deviam ser evitadas as grandes aglomerações de pessoas para evitar a propagação da doença, uma vez que a sua transmissão se fazia, fundamentalmente, de pessoa para pessoa; consideravam que, normalmente, as epidemias de gripe se moviam de norte para sul e para oeste, e que a tendência era que a uma vaga benigna se seguisse o aparecimento de surtos mais letais. Achavam, ainda, que entre outras particularidades, a pneumônica era altamente contagiosa, se difundia muito rapidamente, tinha um caráter ondulatório, aparecia de forma repentina e atacava sobretudo os adultos; e que as mulheres grávidas e as pessoas que padeciam de outras doenças, como a tuberculose, corriam mais riscos.

Em matéria de prevenção, os médicos defendiam um conjunto variado de medidas: o isolamento dos infectados e o internamento compulsivo; se permanecessem em casa, deveriam privilegiar compartimentos amplos, bem iluminados e ventilados; a alimentação devia ser bem acautelada, sendo recomendado o consumo de grandes quantidades de leite; 29 os resfriados e os ajuntamentos de pessoas deviam ser evitados; eram aconselhados cuidados redobrados com a higiene; era admitido o uso de máscaras e o recurso a fármacos usados para tratar outras enfermidades, como a malária ou a sífilis (e.g. quinino). Por último, alguns apostavam na vacina: "São o processo do futuro, o único eficaz quando aplicado em grande escala" ${ }^{30}$

Os mortos também eram motivo de preocupação. Em muitos lugares, os cadáveres amontoavam-se e ficavam vários dias a aguardar por enterro, pondo em risco a saúde pública. ${ }^{31}$ Os coveiros, com medo do contágio, recusavam-se a sepultá-los. Foram abertas valas comuns e, onde ainda não havia cemitérios, eram enterrados nos adros das igrejas, o que também originava problemas sanitários. A recorrência da morte levou a que até os sinos deixassem de tocar aos finados. ${ }^{32} \mathrm{O}$ quadro descrito era agravado pela publicação de notícias falsas, que serviam para confundir a população, espalhar o medo e complicar o combate à epidemia. ${ }^{33}$

O medo e o espectro da morte levaram a população a procurar refúgio e conforto na religião, por meio de missas, preces públicas, promessas e procissões. Muita gente encarou a pandemia como um castigo divino e, por isso, era necessário obter o perdão de Deus. Todavia,

28 TORRES, Cesar Augusto Fernandes. Considerações sobre a gripe. Porto: Tip. a vapor da Enciclopédia Portuguesa, 1920. p. 17.

29 DIAS, José Domingos. A pandemia gripal de 1918. 1919. Tese (Doutorado em Medicina) - Faculdade de Medicina, Universidade do Porto, Porto, 1919. p. 125.

30 COSTA, Celestino da. Estudo da gripe epidêmica. Porto: Tip. a vapor da Enciclopédia Portuguesa, 1920. p. 117.

31 O Algarve: semanário independente, Faro, n. 354, 3 nov. 1918.

32 GARNEL, Maria Rita Lino. Morte e Memória da Pneumônica de 1918. In: SOBRAL et al., op. cit., p. 221-235.

33 O Algarve: semanário independente, Faro, n. 355, 10 nov. 1918. 
no pico da doença, as cerimônias religiosas também foram proibidas e as igrejas fechadas, como forma de evitar as multidões. Terminada a ameaça, havia que agradecer a Deus a preservação da vida e da saúde. Então, em algumas localidades, houve celebrações de ação de graças e foram organizados bandos de precatórios (grupos de pessoas que andavam pelas ruas a implorar pelo exercício da caridade pública).

Entre os repositórios de memória da pneumônica estão os jornais. ${ }^{34}$ Apesar dos elevados números de analfabetismo que o país apresentava, era comum a leitura pública dos jornais em tabernas e cafés. Na altura, vigorava a censura imposta por Sidônio Pais, o que explica a ausência de notícias de primeira página na imprensa de grande tiragem. Todavia, nos periódicos locais e regionais, as novidades abundavam, permitindo a construção de uma memória, ainda que condicionada pelas interferências políticas em algumas publicações. Num contexto adverso aos planos político, econômico, social e sanitário, os jornais desempenhavam uma importante função, não apenas informativa, mas também pedagógica. Assim, além de noticiarem a evolução da doença, serviam também de veículo de transmissão de recomendações sobre os cuidados a ter, seguindo os apelos dos médicos e das autoridades da saúde, além de, sempre que fosse caso disso, publicarem artigos de opinião, nem sempre favoráveis, sobre a atuação dos médicos e dos responsáveis políticos e sanitários, bem como sobre as medidas tomadas.

Importa, ainda, referir que, nos séculos XIX e XX, os jornais tenderam a sobrevalorizar algumas doenças, conferindo-Ihes mais destaque, em detrimento de outras. A cólera, por exemplo, foi amplamente noticiada, enquanto outras, como o tifo, não mereceram a mesma atenção. ${ }^{35}$ Durante os surtos, também não faltavam textos sobre remédios, terapias e remédios caseiros que iam surgindo, bem como anúncios de iniciativas de cunho filantrópico, algumas das quais promovidas pelos próprios jornais.

\section{Conclusão}

TAL COMO ACONTECEU NO RESTO MUNDO, também em Portugal a pneumônica atemorizou a população. O medo resultava, desde logo, das próprias características da pandemia. Uma delas tinha a ver com o fato de se propagar muito rapidamente e atacar os jovens adultos, com idades compreendidas entre os 20 e 40 anos de idade, ao passo que, até então, a gripe vitimava sobretudo idosos e doentes. Ao retirar a vida de jovens na pujança da idade, a pneumônica destruía famílias e agravava ainda mais a situação dos estratos sociais mais desfavorecidos. Por outro lado, os medicamentos conhecidos não surtiam efeito e as medidas

34 LIMA, Maria Luísa; CASTRO, Paula; SOUSA, Paulo Silveira; SOBRAL, José Manuel. A febre da gripe nos jornais: processos de amplificação social do risco. In: SOBRAL et al., op. cit., p. 255-277.

35 ALMEIDA, Maria Antónia Pires de. A epidemia de cólera de 1853-1856 na imprensa portuguesa. História, Ciências, Saúde - Manguinhos, Rio de Janeiro, v. 18, n. 4, p. 1.057-1.071, 2012; ALMEIDA, Maria Antônia Pires de. O Porto e as epidemias: saúde e higiene na imprensa diária em períodos de crise sanitária, 1854-56, 1899, 1918. Revista de História da Sociedade e da Cultura, n. 12, p. 371-391, 2012; Idem. As epidemias nas notícias em Portugal: cólera, peste, tifo, gripe e varíola, 1854-1918. História, Ciências, Saúde - Manguinhos, Rio de Janeiro, v. 21, n. 2, p. 687-708, 2014. 
adotadas não travavam o avanço da enfermidade, o que levou ao descrédito da medicina convencional e ao questionamento das decisões dos responsáveis políticos e sanitários.

Em alguns estados, a pandemia provocou fortes restrições sociais e limitações às liberdades individuais. Houve fechamento de teatros, cinemas, salões, escolas e o adiamento da abertura do ano letivo; houve imposição de quarentenas e cordões sanitários e foram proibidos os ajuntamentos; procurou-se sensibilizar as pessoas para que evitassem a tosse, os espirros, os beijos e as conversas em espaços públicos; foi imposto o uso de máscaras em alguns locais; a economia mundial entrou em crise; e a fome chegou a várias regiões do globo. Mas assistiu-se também ao desenvolvimento da medicina alternativa e do movimento sanitarista, bem como à procura de estilos de vida saudáveis, intensificando-se o gosto pelo ar puro, pela natureza e pelos desportos ao ar livre.

Entre as principais vítimas, estavam os órfãos, as viúvas e os pobres, que viram sua condição agravar-se. Segundo algumas perspectivas, a pneumônica deixou perturbações mentais nos sobreviventes, ainda que faltem estudos que comprovem sua relação com o desenvolvimento de doenças mentais.

Mudou também a perspectiva sobre a morte, que durante meses se tornou uma ameaça constante. Intelectuais e artistas também foram tocados e até vitimados pela pandemia, e pela ideia de morte. No campo artístico, assistiu-se ao uso do corpo como instrumento de comunicação e de transmissão de sensações e emoções, uma tendência patente em vários movimentos que marcam a arte do século XX. Instalou-se o pessimismo e a descrença no homem e numa determinada ideia de progresso.

A gripe regressará em 1957, com a gripe asiática, que vitimou 2 milhões de pessoas e que também atingiu Portugal. ${ }^{36}$ Na década seguinte, em 1968, surgiu a gripe de Hong-Kong, que causou a morte a um milhão de pessoas. Já nos anos 1990, apareceu a gripe das aves. Foram os surtos verificados nos finais do século $X X$ que contribuíram para o resgate das epidemias do passado, particularmente da pneumônica. O que nos leva a concluir com algumas questões: por que motivo(s) caem as epidemias no esquecimento da história? Será a morte por doença mais "natural" do que a que acontece em circunstâncias traumáticas, como as guerras? Por que motivo(s) não se lembram as vítimas das epidemias, não se constroem estátuas nem se reservam dias no calendário em sua memória? O sofrimento individual e coletivo poderá levar as pessoas e as sociedades a não quererem recordar esses acontecimentos? A pneumônica é indissociável da I Guerra Mundial. Terminado o conflito, continuou a ceifar muitos milhões de vidas, mas sobre a gripe escreveu-se incomparavelmente menos do que sobre a guerra.

Recebido em 27/06/2020

Aprovado em 12/08/2020

36 GEORGE, Francisco. História da gripe. Direção Geral de Saúde, 2014. 